\title{
Highly sensitive refractive index sensor based on SPR with silver and titanium dioxide coating
}

\section{Guangyao Wang \\ Tianjin University \\ Ying Lu \\ Tianjin University \\ Jianquan Yao \\ Tianjin University}

haiming yang ( $\nabla$ hayang@tju.edu.cn )

Tianjin University https://orcid.org/0000-0001-6261-3097

\section{Research Article}

Keywords: Optical fiber sensor, Surface plasmon resonance, Refractive index sensor, Photonic crystal fiber

Posted Date: March 9th, 2021

DOI: https://doi.org/10.21203/rs.3.rs-171313/v1

License: (1) (1) This work is licensed under a Creative Commons Attribution 4.0 International License. Read Full License 


\title{
Highly sensitive refractive index sensor based on SPR with silver and titanium dioxide
}

\section{coating}

\author{
HAIMING YANG, ${ }^{1,2}$ GUANGYAO WANG, ${ }^{1,2}$ YING LU, ${ }^{1,2,{ }^{*}}$ AND JIANQUAN \\ $\mathrm{YAO}^{1,2}$ \\ ${ }^{1}$ Institute of Laser and Opto-Electronics, College of Precision Instruments and Opto-Electronics \\ Engineering, Tianjin University, Tianjin 300072, China \\ ${ }^{2}$ Key Laboratory of Opto-Electronics Information Technology, Tianjin University, Ministry of \\ Education, Tianjin 300072, China \\ *Corresponding author: luying@tju.edu.cn
}

\begin{abstract}
A surface plasmon resonance (SPR) sensor based on dual-layered air hole shaped photonic crystal fiber (PCF) is proposed to realize the simultaneous measurement of refractive index (RI). The plasma materials silver $(\mathrm{Ag})$ and titanium dioxide $\left(\mathrm{TiO}_{2}\right)$ were sequentially coated on the outer surface of PCF to obtain enhanced sensing properties. By carefully adjusting the geometrical parameters, the simulation results show a maximum wavelength sensitivity of $72000 \mathrm{~nm} / \mathrm{RIU}$ for analyte refractive indices ranging from 1.26 to 1.365 , which realizes the high-sensitivity sensing in the visible to near-infrared optical band. Moreover, the sensor attains a maximum figure of merit (FOM) of 229 and RI resolution of $1.29 \times 10^{-6}$. This work shows great potential for real-time, affordable, and accurate measurement in biomedical, biological and organic chemical domains.
\end{abstract}

Keywords: Optical fiber sensor; Surface plasmon resonance; Refractive index sensor; Photonic crystal fiber

\section{Introduction}

Over the past few years, surface plasmon resonance (SPR) sensing technology based on photonic crystal fibers (PCFs) has achieved notable applications in environmental monitoring, medical diagnostics, biochemical analysis, and food safety testing due to its outstanding performance and wide range of utilization (Cao et al. 2018; Liu et al. 2017b; Tong et al. 2018). The SPR can be characterized as the collective oscillation of free electrons at the metal- 
dielectric interface (Islam et al. 2018). Resonance occurs when the propagation constant of the incident electromagnetic photons matches the propagation constant of the surface electron oscillations, in which part of the energy of the incident light is transferred to the surface plasmons (SPs). The resonance conditions depend on the dielectric constant of the metal and the dielectric constant of the medium contacting it. When the dielectric around the metal changes, the SPR resonance condition changes accordingly. Compared to conventional prism SPR sensors (Homola et al. 1999), PCF-SPR sensors have the advantages of compact structure, label-free sensing, fast response rate, high sensitivity, and high resolution (Zhao et al. 2017). In addition, the structure can be optimized by changing the internal structure and coating with different materials to enhance the coupling between core fundamental mode and plasma mode and thus enhance the performance. The most commonly used plasma materials are gold(Au) and silver(Ag) which are coated on the PCF surface to stimulate SPR phenomena (Dash,Jha 2014; Lu et al. 2015; Liu et al. 2019). Gold and silver have their own advantages, the former showing chemical stability and biocompatibility, while silver has sharper resonance loss peaks, yet it tends to corrosion in a humid environment which affects the detection accuracy (Rifat et al. 2015). However, coating a high dielectric titanium dioxide $\left(\mathrm{TiO}_{2}\right)$ film outside the metal layer can protect the silver from corrosion, but also can significantly enhance the performance of the SPR sensor (Wang et al. 2019; Zhou et al. 2020). SPR based PCF sensors have two main types of sensing mechanisms which are internal and external sensing. When analyte is filled in air holes inside the PCF to form sensing channels, it is called internal sensing, while when the analyte directly contacts the outer surface of the PCF, this type of is referred to as external sensing. There are several limitations with internal sensing, such as the difficulty of evacuating and refilling the selected air holes during measurement, and the difficulty of manufacturing an internal metal coated PCF-SPR sensor (Rifat et al. 2017). Therefore, external sensing is more valuable and promising.

In this work, we propose a novel silver and $\mathrm{TiO}_{2}$ coated PCF-SPR sensor based on external sensing and operating at the visible to near-infrared optical band. Both theory and experiments demonstrated that the penetration depth of the evanescent field is deeper in the near-infrared band, which results in enhanced detection properties, and the appropriate laser source is also accessible conveniently and affordably (Ziblat et al. 2006). Considering that it is difficult to discern the $x$ polarization and $y$ polarization in actual measurement, we propose a fully symmetric structure with circular core in order to obtain a high-sensitivity and easily fabricated sensor. In order to manufacture uniform coatings and also for practical applications, Ag and $\mathrm{TiO} 2$ films are sequentially deposited on the external surface of the fiber. In order to obtain optimal performance, we carefully optimized numerous geometric parameters, such as fiber core diameter, pitch distance, analyte channel thickness and $\mathrm{Ag} / \mathrm{TiO}_{2}$ coating thickness. 


\section{Structure and theoretical modeling}

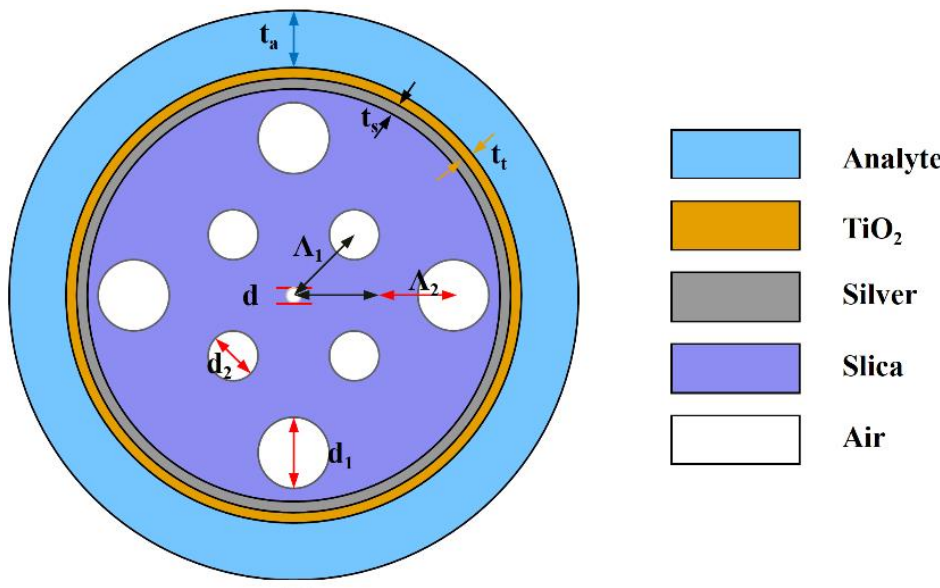

(a)

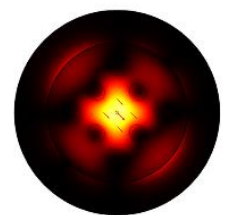

(b)

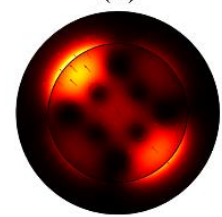

(d)

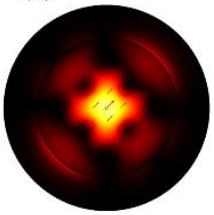

(c)

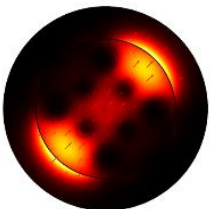

(e)

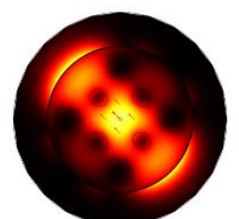

(f)

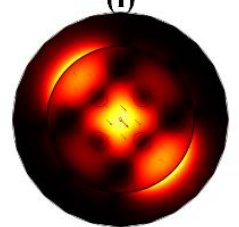

(h)

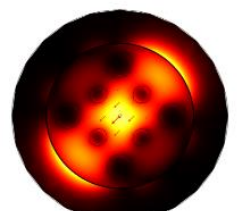

(g)

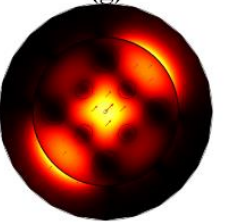

(i)

High

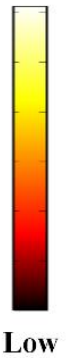

Fig. 1. Schematic of the cross section (a),core mode (b-c) and SPP mode(d-e) for analyte RI 1.26 and core mode (f-g) and SPP mode (h-i) for analyte RI 1.36 at $d=0.18 \mu \mathrm{m}, d_{1}=1.5 \mu \mathrm{m}$, $d_{2}=1.0 \mu \mathrm{m}, \Lambda_{1}=1.8 \mu \mathrm{m}, \Lambda_{2}=1.25 \mu \mathrm{m}, t_{\mathrm{s}}=20 \mathrm{~nm}, t_{\mathrm{t}}=28 \mathrm{~nm}$, and $t_{\mathrm{a}}=2.0 \mu \mathrm{m}$, respectively.

In this paper, we employ finite element method (FEM) based COMSOL v5.4a software to conduct modeling and performance evaluation. The schematic of proposed $\mathrm{Ag} / \mathrm{TiO}_{2}$ coated PCF-SPR sensor is illustrated in Fig. 1(a). Upon a silica substrate, a symmetrical structure with a circular core and two layers of circular air holes is introduced. Differing diameters of air holes $\left(d_{1}\right.$ and $d_{2}$ ) have a significant influence on optical mode coupling and propagation of light, which will be discussed in later sections. The air holes of diameter $d_{1}$ are designed to confine the energy of the core mode, makes the energy divided into four channels coupled to the SPP mode, thus the performance of sensor improved with the intense interaction between fundamental mode and plasmonic mode. The air holes of diameter $d_{2}$ are utilized to minimize confinement loss. A layer of silver film is assembled on the cladding surface. Then a $\mathrm{TiO}_{2}$ film is attached to the silver film, and the additional $\mathrm{TiO}_{2}$ film enhances the performance of the sensor compared to a mono-layer metal film. In our proposed sensor, the analyte is directly contacted with the 
external surface of the sensor, which avoids the inadequacies of internal sensing such as difficulty in cleaning and difficulty in ensuring uniform distribution of the analyte.

We optimize the core diameter $(d)$, air hole diameters $\left(d_{1}\right.$ and $\left.{ }_{2}\right)$, pitch distance $\left(\Lambda_{1}\right.$ and $\left.\Lambda_{2}\right)$ silver $\left(t_{\mathrm{s}}\right) \operatorname{TiO} 2\left(t_{\mathrm{t}}\right)$ and analyte $\left(t_{\mathrm{a}}\right)$ thickness to determine the optimal parameter. After a detailed investigation, we choose $d=0.18 \mu \mathrm{m}, d_{1}=1.5 \mu \mathrm{m}, d_{2}=1.0 \mu \mathrm{m}, \Lambda_{1}=1.8 \mu \mathrm{m}, \Lambda_{2}=1.25 \mu \mathrm{m}, t_{\mathrm{s}}$ $=20 \mathrm{~nm}, t_{\mathrm{t}}=28 \mathrm{~nm}, t_{\mathrm{a}}=2.0 \mu \mathrm{m}$ as the optimum. A brief discussion of the optimization analysis over these parameters is presented in Section 3.

The refractive index of pure silica can be described by Sellmeier equation (Liu et al. 2017a):

$$
n^{2}-1=\frac{0.6961663 \lambda^{2}}{\lambda^{2}-0.0684043^{2}}+\frac{0.4079426 \lambda^{2}}{\lambda^{2}-0.1162414^{2}}+\frac{0.8974794 \lambda^{2}}{\lambda^{2}-9.896161^{2}}
$$

where $n$ presents the refractive index of silica and $\lambda$ stands for the wavelength of the incident light.

The material dispersion of silver can be computed by the Lorentz-Drude's model (Zong,Zhang 2019; Laroche,Girard 2006):

$$
\varepsilon(\omega)=\varepsilon_{\infty}-\frac{\omega_{p}^{2}}{i \omega \gamma+\omega^{2}}-\frac{\Delta \Omega_{L}^{2}}{\left(\omega^{2}-\Omega_{L}^{2}\right)+i \Gamma_{L} \omega}
$$

where $\varepsilon_{\infty}=2.4064$ is the permittivity of silver, $\omega_{p}$ and $\gamma$ are the usual constants of the Drude model where $\omega_{p} / 2 \pi=2214.6 \mathrm{THz}$ and $\gamma / 2 \pi=4.8 \mathrm{THz}, \Omega_{L}$ and $\Gamma_{L}$ donate the frequency and spectral width of the Lorentz oscillator, where $\Omega_{L} / 2 \pi=1330.1 \mathrm{THz}$, and $\Gamma_{L} / 2 \pi=620.7 \mathrm{THz}$, $\omega_{p}$ and $\gamma$ are the usual constants of the Drude model, where $\omega_{p} / 2 \pi=2214.6 \mathrm{THz}$, and $\gamma / 2 \pi=$ $4.8 \mathrm{THz}, \Delta=1.6604$ is the strength of the Lorentz oscillator.

The RI of $\mathrm{TiO}_{2}$ can be calculated as follows (Wang et al. 2019),

$$
n^{2}=5.913+\frac{0.2441}{\lambda^{2}-0.0803}
$$

Where $\mathrm{n}$ presents the effective refractive index of $\mathrm{TiO}_{2}$ and $\lambda$ stands for the wavelength of the incident light.

The confinement loss can be calculated using the imaginary part of the core mode complex RI by the following equation (Yang et al. 2015),

$$
L=8.686 \times \frac{2 \pi}{\lambda} \times \operatorname{Im}\left(n_{e f f}\right) \times 10^{4}, d B / \mathrm{cm}
$$


Where $\mathrm{L}$ indicates the confinement loss, $\lambda$ means the incident wavelength, unit of micron. $\operatorname{Im}\left(n_{\text {eff }}\right)$ denotes the imaginary part of the complex refractive index.

The wavelength interrogation (WI) method is used to evaluate the performance of the proposed sensor, and thus the wavelength sensitivity can be calculated by the following equation (Yang et al. 2015),

$$
S_{(\mathrm{w})}=\frac{\Delta \lambda_{p e a k}}{\Delta n_{a}}
$$

Where, $\Delta \lambda_{\text {peak }}$ stands for the shift in resonance peaks and $\Delta n_{a}$ represents for the variation of analyte RI respectively.

Resolution is also an important parameter that reflects the ability of the sensor to detect a small RI change of proposed sensor. The resolution of a sensor can be described by the following equation (Momota,Hasan 2018),

$$
R=\frac{\Delta \mathrm{n}_{a} \Delta \lambda_{\text {min }}}{\Delta \lambda_{\text {peak }}}
$$

where, $R$ indicates the sensor resolution, $\Delta n_{a}$ represents the variation of analyte RI, $\Delta \lambda_{\min }$ represents the minimum wavelength resolution, assumed to be $0.1 \mathrm{~nm}$, and $\Delta \lambda_{\text {peak }}$ represents the difference in resonance peak wavelength.

Note that, the overall performance of a sensor is defined in terms of figure of merit (FOM), which is the ratio of sensitivity to full width at half minima (FWHM), the FOM can be calculated by S/FWHM. Generally, to realize a high performance sensor the FOM should be as high as possible, which can be obtained with increasing sensitivity and decreasing FWHM.

The fabrication of the proposed sensor is not complicated. The different sized circular shaped air holes based in silica substrate can be accomplished by the stack-and-draw method (Mahdiraji et al. 2014; Knight 2003), and the stacked arrangement is illustrated in Fig. 2(a). The 3D structure of the microstructured fiber obtained by the stack-and-draw method is shown in Fig. 2(b). Moreover, femtosecond laser etching (Zhang et al. 2019) and 3D printing (EbendorffHeidepriem et al. 2014) have also been applied to the fabrication of PCF most recently. Several convenient methods can be used of obtaining thin silver and $\mathrm{TiO}_{2}$ layers on the outer surface of the sensor, such as chemical vapor deposition (CVD) and high-pressure microfluidic chemical deposition, and magnetron sputtering coating (Bayindir et al. 2004; Sazio et al. 2006; Zhang et al. 2007; Xie et al. 2017). Therefore, the manufacture of proposed sensor can be realized by using available fabrication technologies. 


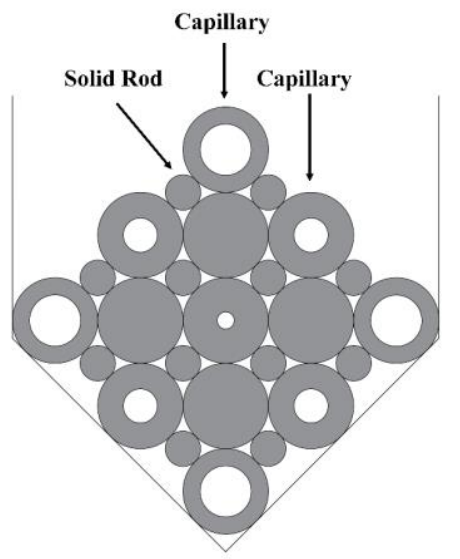

(a)

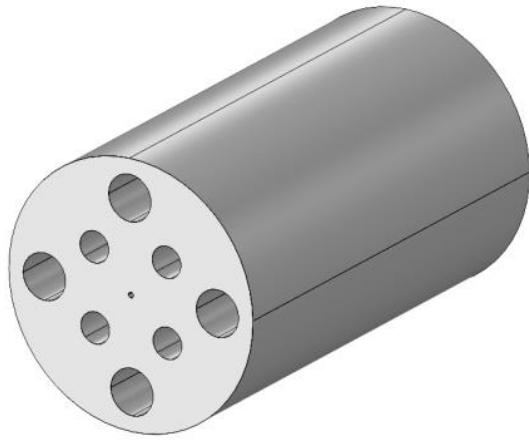

(b)

Fig. 2. (a) Stacked structure of the sensor. (b) 3D illustration of the sensor.

\section{Investigation of sensor performance by optimizing different geometric parameters}

Firstly, we analyzed the distribution of evanescent field, which indicated that there was a strong coupling between the fundamental mode and the SPP mode as shown in Fig. 1. At the resonance wavelength, Fig. 1(b-e) shows the field distributions at $n_{\mathrm{a}}=1.26$ RIU, and Fig. 1(f-i) shows the field distributions $n_{\mathrm{a}}=1.36$ RIU. Fig. 1(f-g) shows the fundamental mode distribution, and Fig. 1(h-i) shows the SPP mode distribution. It can be seen that the SPP mode energy is higher in this case compared to $n_{\mathrm{a}}=1.26 \mathrm{RIU}$, indicating that the mode field is more strongly coupled at $n_{\mathrm{a}}=1.36 \mathrm{RIU}$ than at $n_{\mathrm{a}}=1.26 \mathrm{RIU}$. Thus, stronger detection performance is achieved when the RI of the analyte is higher than 1.26 RIU. Since the proposed PCF-SPR sensor adopts symmetrical structure, the $x$ polarization equals the $y$ polarization to some degree which can be confirmed by the field distribution in Fig. 1, so the following discussion focuses on single one of the polarizations.

The dispersion profile for fundamental core mode, plasmonic mode and confinement loss as a function of wavelength is shown in Fig. 3(a). The resonance loss curve obtains a sharp peak when the effective RI curves of core fundamental mode and SPP mode cross over, and the loss peak can be applied to detection of analytes effectively and easily. Fig. 3(b) shows the confinement loss characteristics of the analyte RI as it changes from 1.26 RIU to 1.365 RIU. Notably, the refractive indices of a wide range of common inorganic and organic substances (e.g. water, methanol, ethanol, propanol, ether.) are in the range of 1.33 RIU to 1.365 RIU. Notice that, the characteristics of the loss curves for different RI analytes mainly determine the performance of the PCF-SPR sensor. Fig. 3(b) demonstrates that with the increase of the analyte RI, the resonance loss peak shows red-shift and the loss peak height also increases obviously. 
Note that as the analyte RI changes slightly, the RI of the SPP mode changes as well while the core mode is unchanged, resulting in the phase matching point move to a longer wavelength (Yang et al. 2017). It was apparent that with increasing RI of the analyte, the shift of the resonance loss peak increases, meaning that higher sensing sensitivity can be accomplished. In addition, the maximum wavelength shift of $360 \mathrm{~nm}$ is obtained between the analyte RI of 1.36 RIU and 1.365 RIU. Thereby, the maximum wavelength sensitivity up to $72000 \mathrm{~nm} / \mathrm{RIU}$ can be obtained at 1.36. In the RI sensing range between 1.26 RIU and 1.365 RIU, the maximum resolution of the SPR sensor is $1.39 \times 10^{-6} \mathrm{RIU}$ with a $0.1 \mathrm{~nm}$ resolution of the spectrometer. Fig. 3(c-d) shows the fitted plots of the resonance wavelength and FOM versus analyte refractive index, with an adjusted R-square of 0.99984 and 0.99606 , respectively. The FOM obtained with different analytes is presented in Table 1, and it can be seen that the maximum FOM of 229 was reached at $n_{a}=1.36$ RIU.

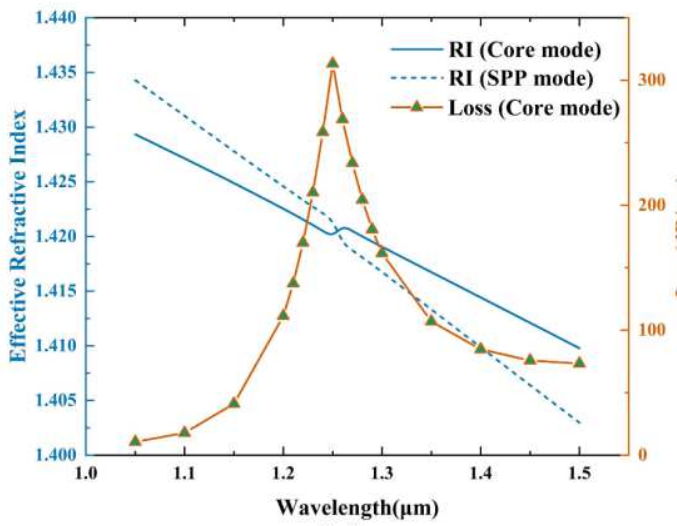

(a)

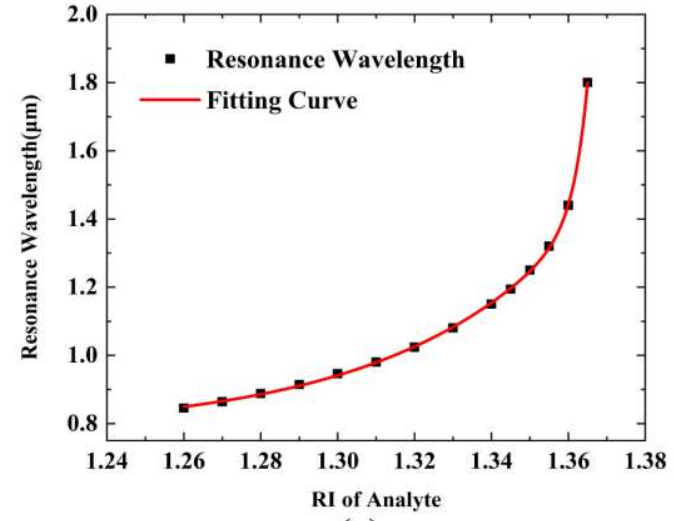

(c)

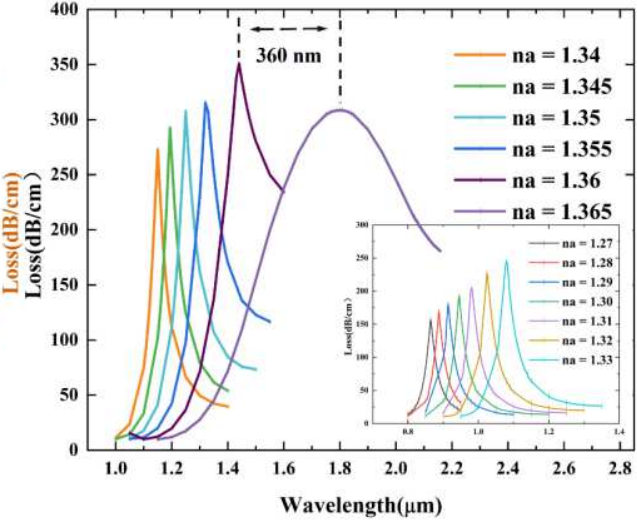

(b)

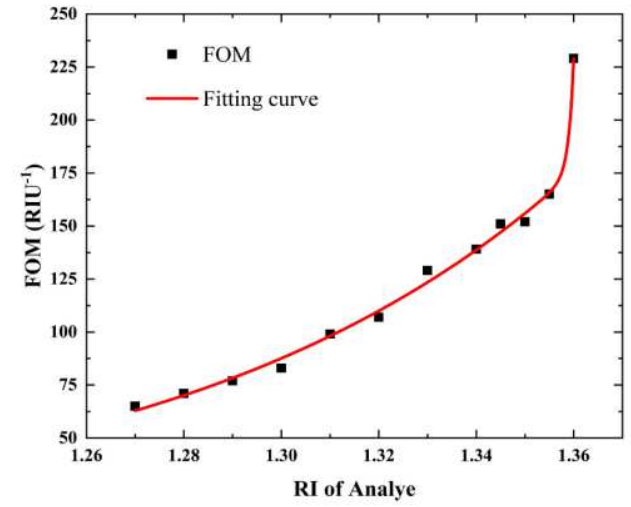

(d)

Fig. 3. Dispersion relation of fundamental core mode, SPP mode, and loss spectra of $n_{a}=1.35$

(a), confinement loss (b), resonance wavelength versus RI of the analyte (c), FOM fitting curve for analyte RI variation (d). 


\subsection{Effect of core diameter on sensing performance}

The influence of different core diameters at the fiber center on the sensing performance is investigated. Note that, in order to directly characterize the performance of the proposed sensor, we choose the RI of 1.36 RIU and 1.365 RIU as a reference. From Fig. 4(a) it can be noticed that the resonance peak with an RI of 1.365 RIU changes significantly when $d$ changes. Overall, for $d=0.18 \mu \mathrm{m}$, the wavelength sensitivity achieves its maximum and the loss peak appears to be sharper. Thus, we choose $d=0.18 \mu \mathrm{m}$ as optimum diameter of circular shaped air hole in the core.

\subsection{Effect of cladding air hole diameter $d 1$ and d2 on sensing performance}

To obtain the optimal diameter of the cladding air holes, we carefully adjusted $d_{1}$ and $d_{2}$ to obtain the respective spectra as shown in Fig. 4(b-c). It is observed that there is only a slight effect of altering $d_{1}$ on the wavelength sensitivity. It is due to the introduction of the large bubbles with $d_{1}$ diameter in order to split the core mode into four channels, thus having a little effect on the coupling between the Core mode and SPP mode. As the $d_{2}$ varies, we observed from the Fig. 4(c) that the shift of the resonance loss peak is quite large and the change in wavelength sensitivity is also significant. The reason is that the air holes with $d_{2}$ diameter is introduced to reduce the confinement loss, which directly affects the energy coupling from the

core mode to the SPP mode, and thus the size of $d_{2}$ has a greater influence on the loss than $d_{1}$.Note that, although a larger wavelength shift is achieved when $d_{2}=0.98 \mu \mathrm{m}$ but the resonance loss is excessively high, so the performance is more acceptable for $d_{2}=1.0 \mu \mathrm{m}$. Therefore, we choose $d_{1}=1.5 \mu \mathrm{m}, d_{2}=1.0 \mu \mathrm{m}$ as the optimal air hole diameters. 

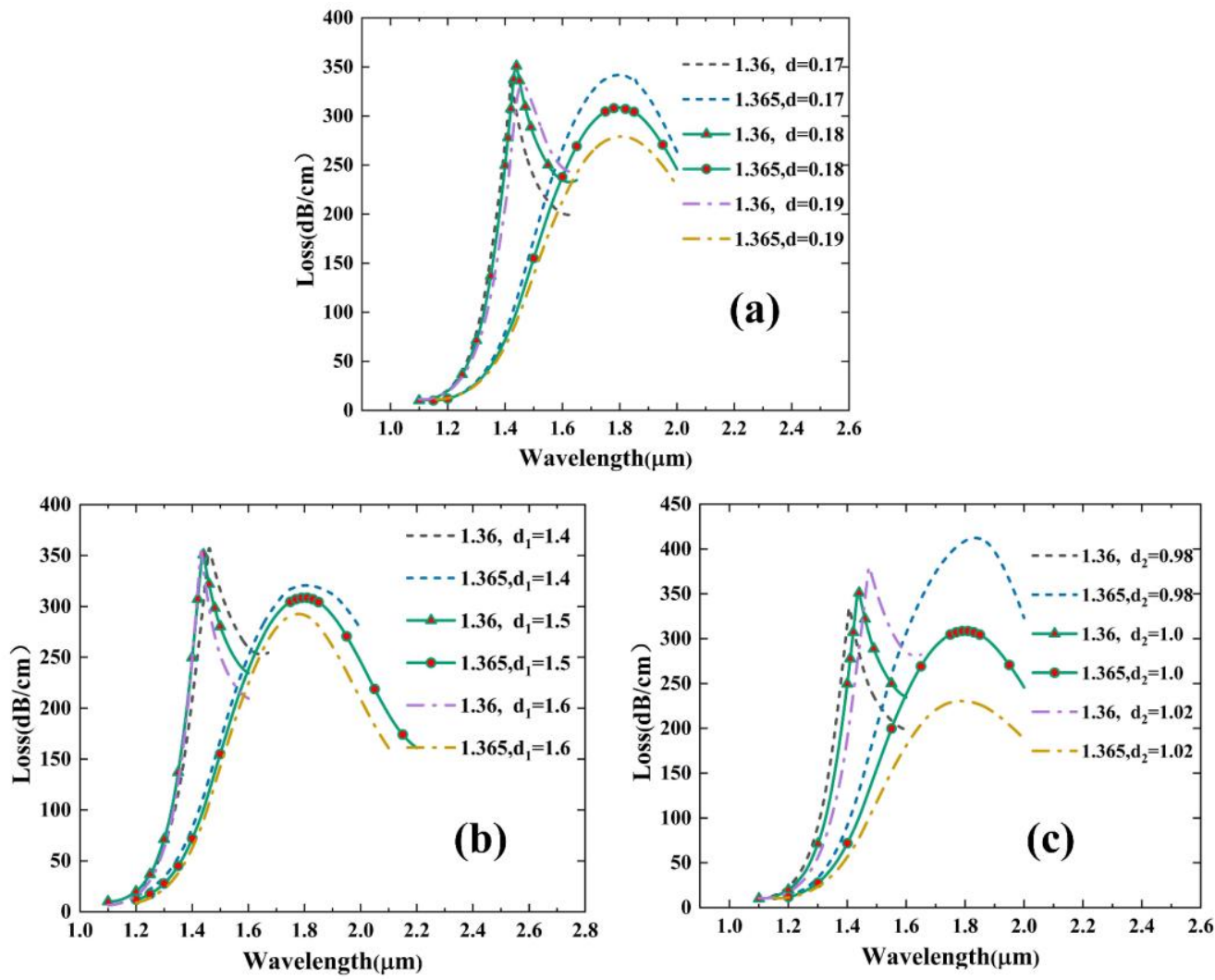

Fig. 4. (a) Confinement loss spectra at different diameter of core. (b-c) Confinement loss spectra for different air hole diameter $d_{1}, d_{2}$.

\subsection{Effect of pitch distance $\Lambda 1$ and $\wedge 2$ on sensing performance}

We also investigated the impact of the pitch distances between air holes. As shown in Fig. 5, with the increase of $\Lambda_{1}$ and $\Lambda_{2}$, the loss peak with refractive index at 1.36 is regularly blueshifted, while the loss peak with refractive index at 1.365 is more variable. After careful tuning, the wavelength sensitivity obtains a maximum when $\Lambda_{1}=1.25 \mu \mathrm{m}$ and $\Lambda_{2}=1.80 \mu \mathrm{m}$, and the loss peak is sharper at the same time. 

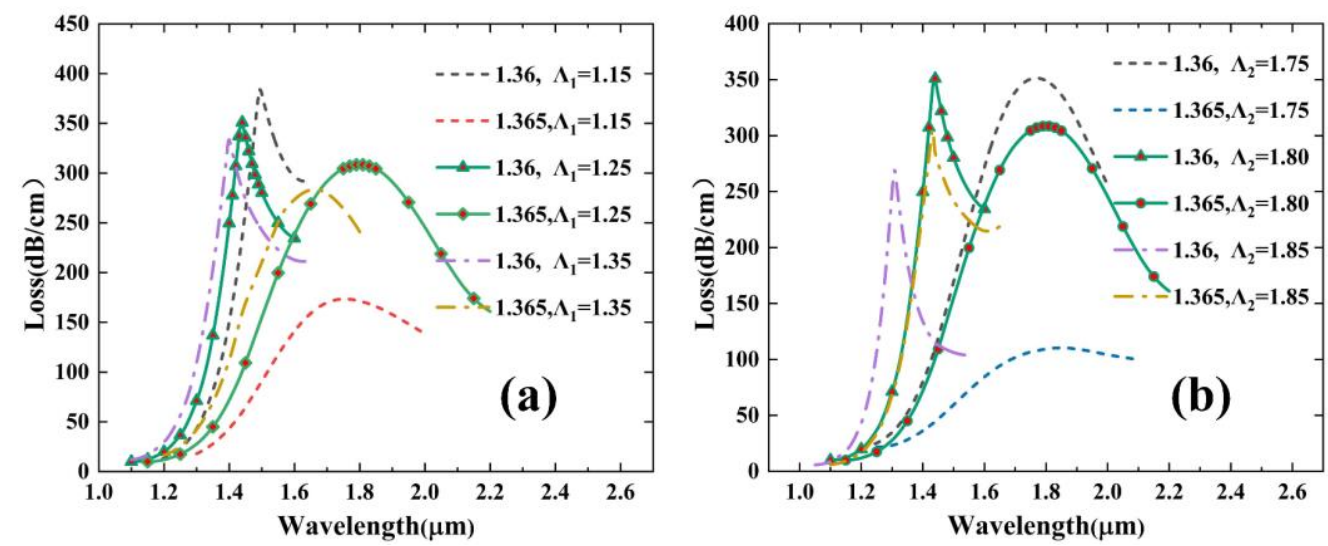

Fig. 5. (a-b) Confinement loss spectra with varying pitch distance $\Lambda 1, \Lambda 2$.

\subsection{Effect of silver and TiO2 thickness on sensing performance}

The thickness of the silver and $\mathrm{TiO}_{2}$ layers plays a critical role in the sensing performance. Some reports indicate that when using a double-layer composite as plasmonic material, a better result can be obtained with a total thickness of approximately $50 \mathrm{~nm}$. Therefore, in order to thoroughly study the influence of the thickness ratio of silver and $\mathrm{TiO}_{2}$ on the sensing characteristics, the thickness of the silver film and the $\mathrm{TiO}_{2}$ film are set at $10 \mathrm{~nm} / 40 \mathrm{~nm}$, $30 \mathrm{~nm} / 20 \mathrm{~nm}, 20 \mathrm{~nm} / 30 \mathrm{~nm}, 10 \mathrm{~nm} / 40 \mathrm{~nm}$ at first. The results are shown in Fig. 6(a). The resonance loss peak differed significantly for different ratios of silver to $\mathrm{TiO}_{2}$ layers, which should be due to the reason that either an overly thick silver layer or an overly thick $\mathrm{TiO}_{2}$ would hinder the energy transfer from the fiber core mode to the SPP mode. The relatively optimal wavelength sensitivity was obtained when $\mathrm{Ag} / \mathrm{TiO} 2=20 \mathrm{~nm} / 30 \mathrm{~nm}$.

Therefore, the loss curves obtained by adjusting $\mathrm{Ag}$ when $\mathrm{TiO} 2$ is $30 \mathrm{~nm}$ and by adjusting $\mathrm{TiO}_{2}$ when $\mathrm{Ag}$ is $20 \mathrm{~nm}$ are investigated respectively, the results are shown in Fig. 6(b-c). When the thickness of $\mathrm{Ag}$ stays at $20 \mathrm{~nm}$, the resonance peak is red-shifted, and the peak loss also decreased as the thickness of $\mathrm{TiO}_{2}$ increases. Similarly, when the thickness of $\mathrm{TiO}_{2}$ stays at 30 $\mathrm{nm}$, the resonance loss peaks also appeared red-shifted variously with the increase of the $\mathrm{Ag}$ film thickness. From the above, we finally chosen $\mathrm{Ag}_{\mathrm{g}}=20 \mathrm{~nm}$ and $\mathrm{TiO}_{2}=28 \mathrm{~nm}$ as the optimal bilayer structure parameters. 

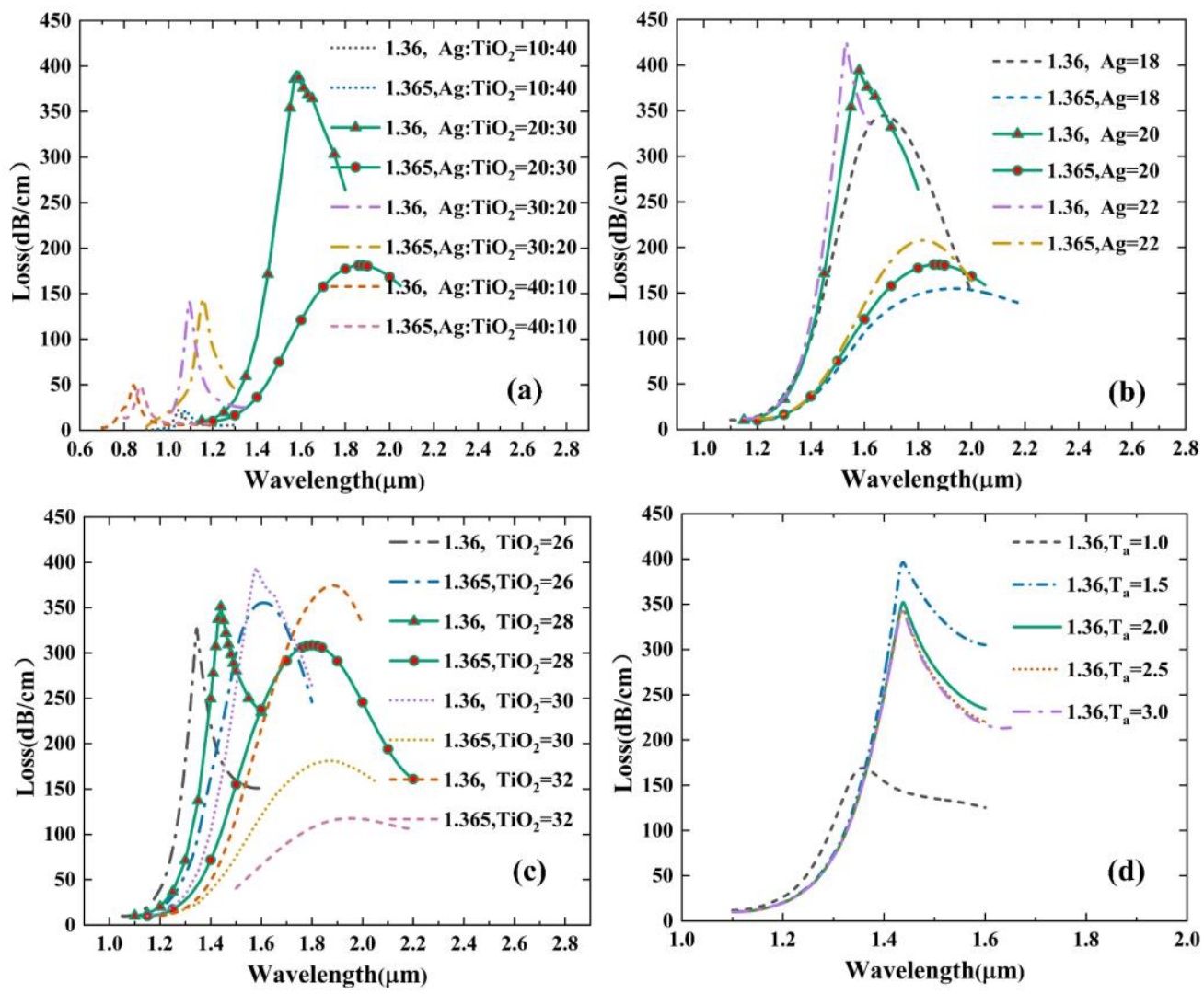

Fig. 6. (a)Confinement loss spectra at different ratio of $\mathrm{Ag}$ and $\mathrm{TiO} 2$ film thickness. (b)Confinement loss spectra for different Ag film thickness at TiO2 film thickness $=30 \mathrm{~nm}$. (c)Confinement loss spectra for different $\mathrm{TiO} 2$ film thickness at $\mathrm{Ag}$ film thickness $=20 \mathrm{~nm}$. (d)Confinement loss spectra at different analyte channel thickness variation.

\subsection{Effect of analyte thickness on sensing performance}

We also investigated the effect of the analyte thickness on the sensing performance. The analyte thickness was set to $1 \mu \mathrm{m}, 1.5 \mu \mathrm{m}, 2 \mu \mathrm{m}, 2.5 \mu \mathrm{m}$, and $3 \mu \mathrm{m}$, respectively, and the loss spectrum was shown in Fig. 6(d).It can be noticed that when $\mathrm{T}_{a}$ is greater than or equal to $2 \mu \mathrm{m}$, the resonance peak changes slightly, whereas when it is less than $2 \mu \mathrm{m}$, the resonance peak changes significantly due to the insufficient energy coupling between core mode and SPP mode. Therefore, we choose $\mathrm{Ta}=2.0 \mu \mathrm{m}$ as the optimal parameter.

A performance comparison of the proposed set of PCF-SPR sensors with prior sensors is presented in Table 1.

Table 1. Comparison of performance of the proposed sensor with prior sensors 


\begin{tabular}{|c|c|c|c|c|c|c|}
\hline Refs. & Sensing Approach & $\begin{array}{c}\text { Wavelength } \\
(\mathrm{nm})\end{array}$ & $\begin{array}{c}\text { RI range } \\
\text { (RIU) }\end{array}$ & $\begin{array}{c}\text { Max. Wave. } \\
\text { Sens.(nm/RIU) }\end{array}$ & $\begin{array}{c}\text { Resolution } \\
\text { (RIU) }\end{array}$ & $\begin{array}{r}\text { FOM } \\
\left(\mathrm{RIU}^{-1}\right)\end{array}$ \\
\hline $\begin{array}{l}\text { (Islam } \\
\text { et al. } \\
2018 \text { ) }\end{array}$ & External & $500-2000$ & $1.33-1.43$ & 62000 & $1.61 \times 10^{-6}$ & 1140 \\
\hline $\begin{array}{l}\text { (Rifat } \\
\text { et al. } \\
\text { 2017) }\end{array}$ & $\begin{array}{c}\text { External } \\
\text { (Side polished) }\end{array}$ & $550-1750$ & $1.33-1.43$ & 46000 & $2.2 \times 10^{-6}$ & N/A \\
\hline $\begin{array}{l}\text { (Zhou } \\
\text { et al. } \\
2018 \text { ) }\end{array}$ & $\begin{array}{c}\text { Internal } \\
\text { (Multi coated PCF) }\end{array}$ & $1150-1550$ & $1.33-1.41$ & 6900 & $1.04 \times 10^{-5}$ & N/A \\
\hline $\begin{array}{l}\text { (Rifat } \\
\text { et al. } \\
\text { 2018) }\end{array}$ & $\begin{array}{c}\text { Internal(selectively } \\
\text { coated) }\end{array}$ & $1200-1550$ & $1.45-1.49$ & 11000 & N/A & 407 \\
\hline $\begin{array}{c}\text { (Liu et } \\
\text { al. } \\
\text { 2018) }\end{array}$ & $\begin{array}{c}\text { External } \\
\text { (side-polished PCF) }\end{array}$ & $1400-1900$ & $1.31-1.37$ & 11750 & $8.51 \times 10^{-6}$ & N/A \\
\hline $\begin{array}{c}\text { (Chu et } \\
\text { al. } \\
\text { 2019) }\end{array}$ & $\begin{array}{c}\text { External } \\
\text { (side-polished } \mathrm{PQF})\end{array}$ & $1300-1700$ & $1.40-1.44$ & 17000 & $5.88 \times 10^{-5}$ & 62.2 \\
\hline $\begin{array}{c}\text { (Li et } \\
\text { al. } \\
\text { 2019) }\end{array}$ & $\begin{array}{c}\text { External } \\
\text { (side-polished PQF) }\end{array}$ & $1470-1630$ & $\begin{array}{l}1.415- \\
1.427\end{array}$ & 34000 & NA/ & 53.9 \\
\hline $\begin{array}{l}\text { This } \\
\text { paper }\end{array}$ & External & $800-2400$ & $\begin{array}{l}1.26- \\
1.365\end{array}$ & 72000 & $1.39 \times 10^{-6}$ & 229 \\
\hline
\end{tabular}

\section{Conclusions}

In this paper, we propose a symmetrical dual-layer air-hole arranged photonic crystal fiber SPR sensor coated with silver and $\mathrm{TiO}_{2}$ externally. The thickness of the silver and titanium dioxide coatings has a significant impact on the sensor performance. Detailed numerical simulation of the sensor shows a maximum wavelength sensitivity of $72000 \mathrm{~nm} / \mathrm{RIU}$ and a maximum FOM of $229 \mathrm{RIU}^{-1}$ within the RI detection range between $1.26 \mathrm{RIU}$ and 1.365 RIU. The sensor can be easily fabricated using existing technology. It is also convenient to conduct relevant practical applications due to the external sensing and symmetrical structure adopted. Thus, the proposed 
sensor demonstrates huge potential in biomedical and chemical fields and can be utilized for the accurate and precise detection in biomedicine and chemistry.

\section{Funding}

This work was supported by the National Basic Research Program of China. (973 Program) (Grant number: 2010CB327801), the National Natural Science Foundation of China (Grant number: 10874128). (Corresponding author: Ying LU) and the Natural Science Foundation of Tianjin (Grant No. 18JCQNJC71200).

\section{Disclosures}

The authors declare no conflicts of interest.

\section{References}

Bayindir, M., Sorin, F., Abouraddy, A.F., Viens, J., Hart, S.D., Joannopoulos, J.D., Fink, Y.: Metal-insulator-semiconductor optoelectronic fibres. Nature 431(7010), 826-829 (2004). doi:10.1038/nature02937

Cao, S.Q., Shao, Y., Wang, Y., Wu, T.S., Zhang, L.F., Huang, Y.J., Zhang, F., Liao, C.R., He, J., Wang, Y.P.: Highly sensitive surface plasmon resonance biosensor based on a low-index polymer optical fiber. Opt Express 26(4), 3988-3994 (2018). doi:10.1364/Oe.26.003988

Chu, S.D., Nakkeeran, K., Abobaker, A.M., Aphale, S.S., Babu, P.R., Senthilnathan, K.: Design and Analysis of Surface-Plasmon-Resonance-Based Photonic Quasi-Crystal Fiber Biosensor for High-Refractive-Index Liquid Analytes. Ieee J Sel Top Quant 25(2) (2019). doi:Artn 6900309

$10.1109 /$ Jstqe.2018.2873481

Dash, J.N., Jha, R.: Graphene-Based Birefringent Photonic Crystal Fiber Sensor Using Surface Plasmon Resonance. Ieee Photonic Tech L 26(11), 1092-1095 (2014). doi:10.1109/Lpt.2014.2315233

Ebendorff-Heidepriem, H., Schuppich, J., Dowler, A., Lima-Marques, L., Monro, T.M.: 3D-printed extrusion dies: a versatile approach to optical material processing. Opt Mater Express 4(8), 1494-1504 (2014). doi:10.1364/Ome.4.001494

Homola, J., Yee, S.S., Gauglitz, G.: Surface plasmon resonance sensors: review. Sensor Actuat B-Chem 54(1-2), 3-15 (1999). doi:Doi 10.1016/S0925-4005(98)00321-9 
Islam, M.S., Sultana, J., Rifat, A.A., Ahmed, R., Dinovitser, A., Ng, B.W.H., EbendorffHeidepriem, H., Abbott, D.: Dual-polarized highly sensitive plasmonic sensor in the visible to near-IR spectrum. Opt Express 26(23), 30347-30361 (2018). doi:10.1364/Oe.26.030347

Knight, J.C.: Photonic crystal fibres. Nature 424(6950), 847-851 (2003). doi:10.1038/nature01940

Laroche, T., Girard, C.: Near-field optical properties of single plasmonic nanowires. Appl Phys Lett 89(23) (2006). doi:Artn 233119

$10.1063 / 1.2403914$

Li, C.G., Yan, B., Liu, J.J.: Refractive index sensing characteristics in a D-shaped photonic quasi-crystal fiber sensor based on surface plasmon resonance. J Opt Soc Am A 36(10), 1663-1668 (2019). doi:10.1364/Josaa.36.001663

Liu, B.L., Lu, Y., Yang, X.C., Yao, J.Q.: Surface plasmon resonance sensor based on photonic crystal fiber filled with gold-silica-gold multilayer nanoshells. Opt Commun 405, 281-287 (2017a). doi:10.1016/j.optcom.2017.08.042

Liu, C., Su, W.Q., Wang, F.M., Li, X.L., Yang, L., Sun, T., Mu, H.W., Chu, P.K.: Theoretical assessment of a highly sensitive photonic crystal fibre based on surface plasmon resonance sensor operating in the near-infrared wavelength. J Mod Optic 66(1), 1-6 (2019). doi:10.1080/09500340.2018.1508776

Liu, M., Yang, X., Zhao, B.Y., Hou, J.Y., Shum, P.: Square array photonic crystal fiberbased surface plasmon resonance refractive index sensor. Mod Phys Lett B 31(36) (2017b). doi:Artn 1750352

$10.1142 / \mathrm{S} 0217984917503523$

Liu, Y.D., Jing, X.L., Li, S.G., Zhang, S.H., Zhang, Z., Guo, Y., Wang, J., Wang, S.: High sensitivity surface plasmon resonance sensor based on D-shaped photonic crystal fiber with circular layout. Opt Fiber Technol 46, 311-317 (2018). doi:10.1016/j.yofte.2018.09.009

Lu, Y., Yang, X.C., Wang, M.T., Yao, J.Q.: Surface plasmon resonance sensor based on hollow-core PCFs filled with silver nanowires. Electron Lett 51(21), 1675-1676 (2015). doi:10.1049/el.2015.2276 
Mahdiraji, G.A., Chow, D.M., Sandoghchi, S.R., Amirkhan, F., Dermosesian, E., Yeo, K.S., Kakaei, Z., Ghomeishi, M., Poh, S.Y., Gang, S.Y., Adikan, F.R.M.: Challenges and Solutions in Fabrication of Silica-Based Photonic Crystal Fibers: An Experimental Study. Fiber Integrated Opt 33(1-2), 85-104 (2014). doi:10.1080/01468030.2013.879680

Momota, M.R., Hasan, M.R.: Hollow-core silver coated photonic crystal fiber plasmonic sensor. Opt Mater 76, 287-294 (2018). doi:10.1016/j.optmat.2017.12.049

Rifat, A.A., Ahmed, R., Mahdiraji, G.A., Adikan, F.R.M.: Highly Sensitive D-Shaped Photonic Crystal Fiber-Based Plasmonic Biosensor in Visible to Near-IR. Ieee Sens J 17(9), 2776-2783 (2017). doi:10.1109/Jsen.2017.2677473

Rifat, A.A., Haider, F., Ahmed, R., Mahdiraji, G.A., Adikan, F.R.M., Miroshnichenko, A.E.: Highly sensitive selectively coated photonic crystal fiber-based plasmonic sensor. Opt Lett 43(4), 891-894 (2018). doi:10.1364/Ol.43.000891

Rifat, A.A., Mahdiraji, G.A., Chow, D.M., Shee, Y.G., Ahmed, R., Adikan, F.R.M.: Photonic Crystal Fiber-Based Surface Plasmon Resonance Sensor with Selective Analyte Channels and Graphene-Silver Deposited Core. Sensors-Basel 15(5), 1149911510 (2015). doi:10.3390/s 150511499

Sazio, P.J.A., Amezcua-Correa, A., Finlayson, C.E., Hayes, J.R., Scheidemantel, T.J., Baril, N.F., Jackson, B.R., Won, D.J., Zhang, F., Margine, E.R., Gopalan, V., Crespi, V.H., Badding, J.V.: Microstructured optical fibers as high-pressure microfluidic reactors. Science 311(5767), 1583-1586 (2006). doi:10.1126/science.1124281

Tong, K., Wang, F.C., Wang, M.T., Dang, P., Wang, Y.X.: Three-core photonic crystal fiber surface plasmon resonance sensor. Opt Fiber Technol 46, 306-310 (2018). doi:10.1016/j.yofte.2018.11.014

Wang, T., Zhang, M.J., Liu, K., Jiang, J.F., Zhao, Y.H., Ma, J.Y., Liu, T.G.: The effect of the $\mathrm{TiO} 2$ film on the performance of the optical fiber SPR sensor. Opt Commun 448, 93-97 (2019). doi:10.1016/j.optcom.2019.05.023

Xie, Q.L., Chen, Y.Z., Li, X.J., Yin, Z., Wang, L.L., Geng, Y.F., Hong, X.M.: Characteristics of D-shaped photonic crystal fiber surface plasmon resonance sensors with different side-polished lengths. Appl Optics 56(5), 1550-1555 (2017). doi:10.1364/Ao.56.001550 
Yang, X.C., Lu, Y., Liu, B.L., Yao, J.Q.: Design of a Tunable Single-Polarization Photonic Crystal Fiber Filter With Silver-Coated and Liquid-Filled Air Holes. Ieee Photonics J 9(4) (2017). doi:Artn 7105108

10.1109/Jphot.2017.2720590

Yang, X.C., Lu, Y., Wang, M.T., Yao, J.Q.: An Exposed-Core Grapefruit Fibers Based Surface Plasmon Resonance Sensor. Sensors-Basel 15(7), 17106-17114 (2015). doi:10.3390/s150717106

Zhang, X., Wang, R., Cox, F.M., Kuhlmey, B.T., Large, M.C.J.: Selective coating of holes in microstructured optical fiber and its application to in-fiber absorptive polarizers. Opt Express 15(24), 16270-16278 (2007). doi:Doi 10.1364/Oe.15.016270

Zhang, Y.F., Liao, C.R., Lin, C.P., Shao, Y., Wang, Y., Wang, Y.P.: Surface plasmon resonance refractive index sensor based on fiber-interface waveguide inscribed by femtosecond laser. Opt Lett 44(10), 2434-2437 (2019). doi:10.1364/Ol.44.002434

Zhao, E.M., Jia, P.P., Ebendorff-Heidepriem, H., Li, H.Y., Huang, P., Liu, D.Y., Li, H.Y., Yang, X.H., Liu, L., Guan, C.Y.: Localized surface plasmon resonance sensing structure based on gold nanohole array on beveled fiber edge. Nanotechnology 28(43) (2017). doi:ARTN 435504

$10.1088 / 1361-6528 / a a 847 \mathrm{a}$

Zhou, L., Zhou, J., Lai, W., Yang, X.D., Meng, J., Su, L.B., Gu, C.J., Jiang, T., Pun, E.Y.B., Shao, L.Y., Petti, L., Sun, X.W., Jia, Z.H., Li, Q.X., Han, J.G., Mormile, P.: Irreversible accumulated SERS behavior of the molecule-linked silver and silverdoped titanium dioxide hybrid system. Nat Commun 11(1) (2020). doi:ARTN 1785 10.1038/s41467-020-15484-6

Zhou, X., Cheng, T.L., Li, S.G., Suzuki, T., Ohishi, Y.: Practical sensing approach based on surface plasmon resonance in a photonic crystal fiber. Osa Continuum 1(4), 13321340 (2018). doi:10.1364/Osac.1.001332

Ziblat, R., Lirtsman, V., Davidov, D., Aroeti, B.: Infrared surface plasmon resonance: a novel tool for real time sensing of variations in living cells (vol 90, pg 2592, 2006). Biophys J 91(2), 776-776 (2006). doi:10.1529/biophysj.106.0900142 
Zong, C.J., Zhang, D.: Analysis of Propagation Characteristics along an Array of Silver Nanorods Using Dielectric Constants from Experimental Data and the Drude-Lorentz Model. Electronics-Switz 8(11) (2019). doi:ARTN 1280

10.3390/electronics 8111280 


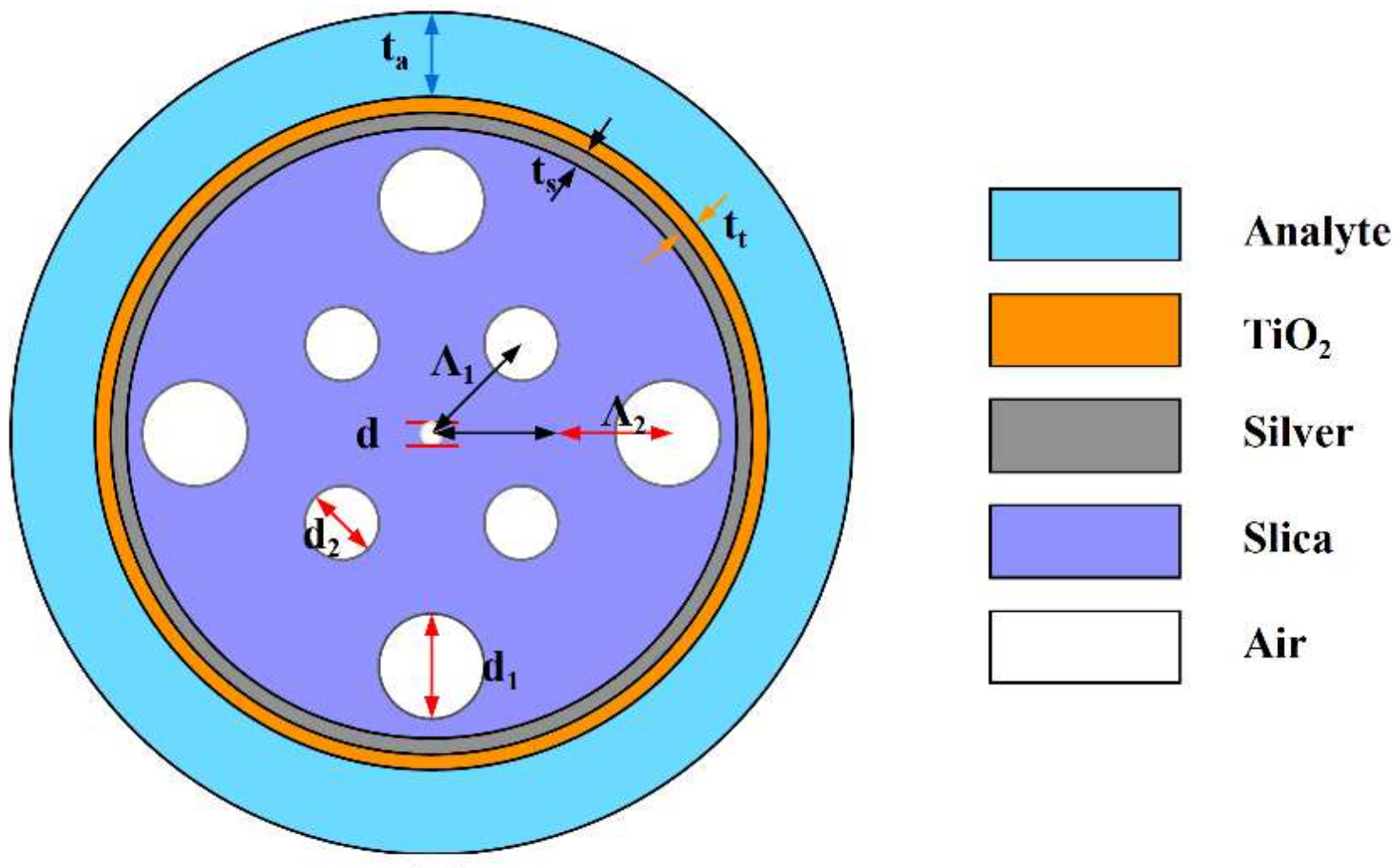

(a)

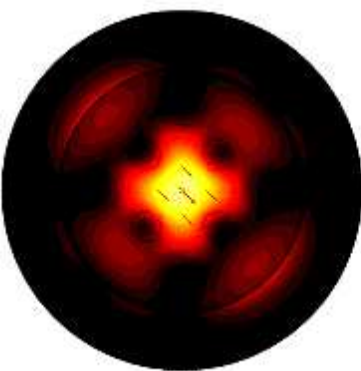

(b)

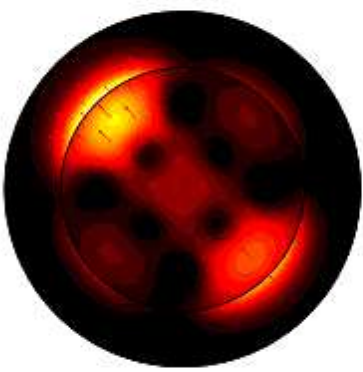

(d)

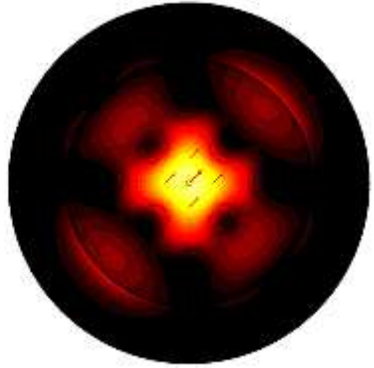

(c)

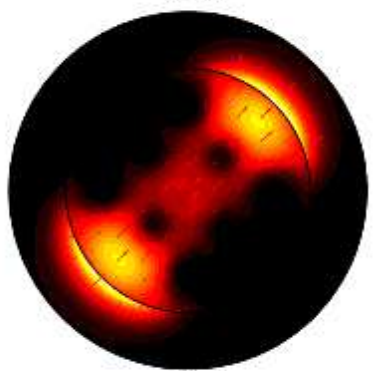

(e)

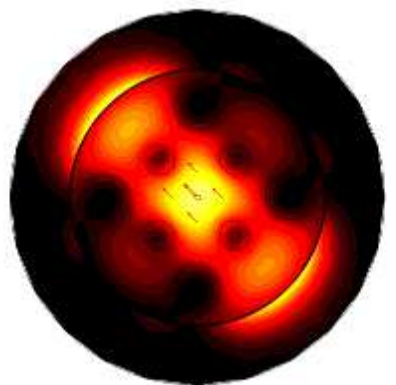

(f)

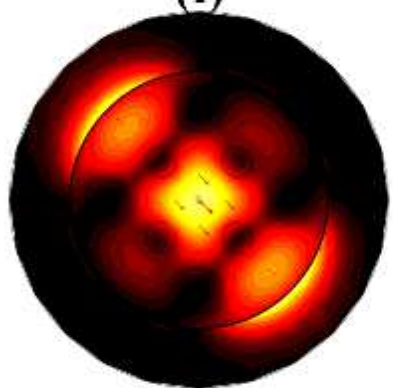

(h)

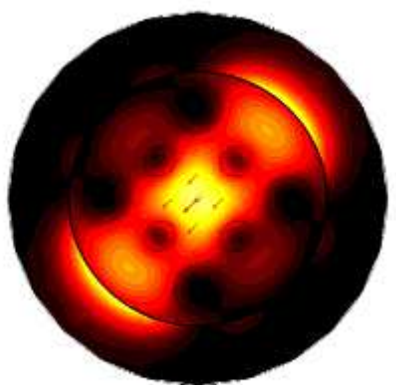

(g)

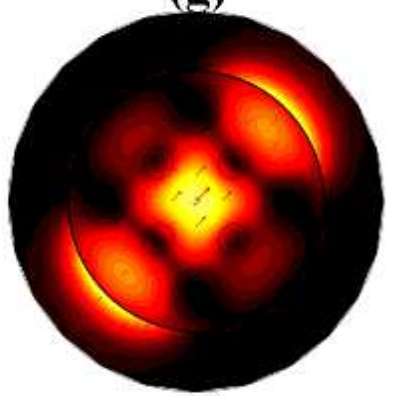

(i)

\section{High}

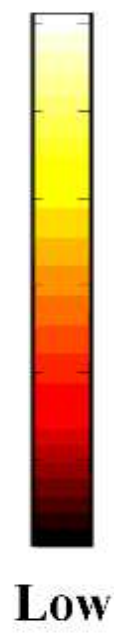

\section{Figure 1}

Schematic of the cross section (a),core mode (b-c) and SPP mode(d-e) for analyte RI 1.26 and core mode (f-g) and SPP mode (h-i) for analyte RI 1.36 at $\mathrm{d}=0.18 \mu \mathrm{m}, \mathrm{d} 1=1.5 \mu \mathrm{m}, \mathrm{d} 2=1.0 \mu \mathrm{m}, \Lambda 1=1.8 \mu \mathrm{m}, \wedge 2=$ $1.25 \mu \mathrm{m}, \mathrm{ts}=20 \mathrm{~nm}, \mathrm{tt}=28 \mathrm{~nm}$, and ta $=2.0 \mu \mathrm{m}$, respectively. 


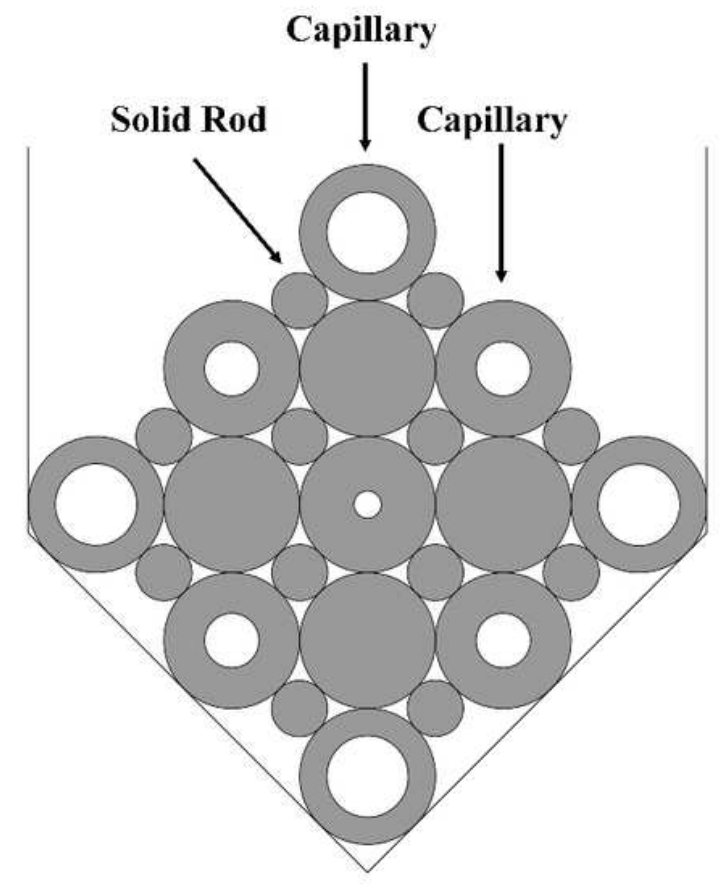

(a)

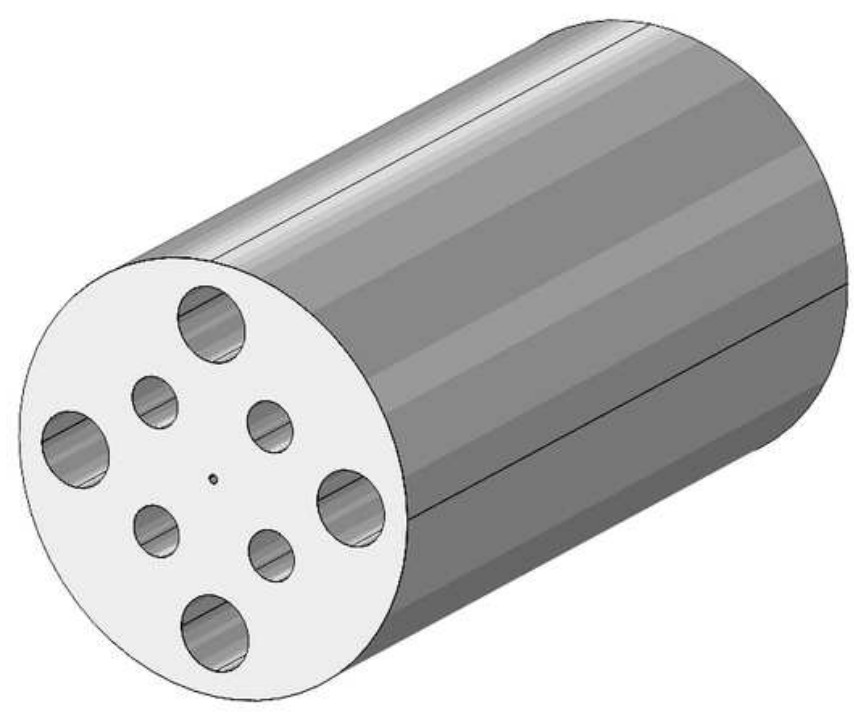

(b)

Figure 2

(a) Stacked structure of the sensor. (b) 3D illustration of the sensor. 


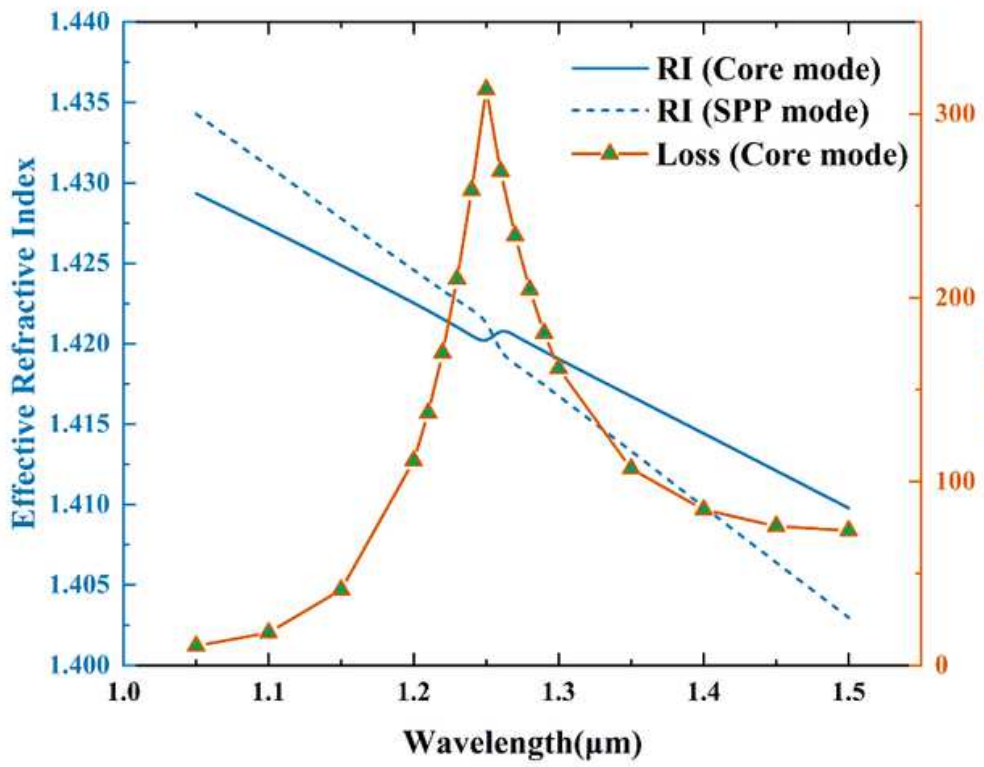

(a)

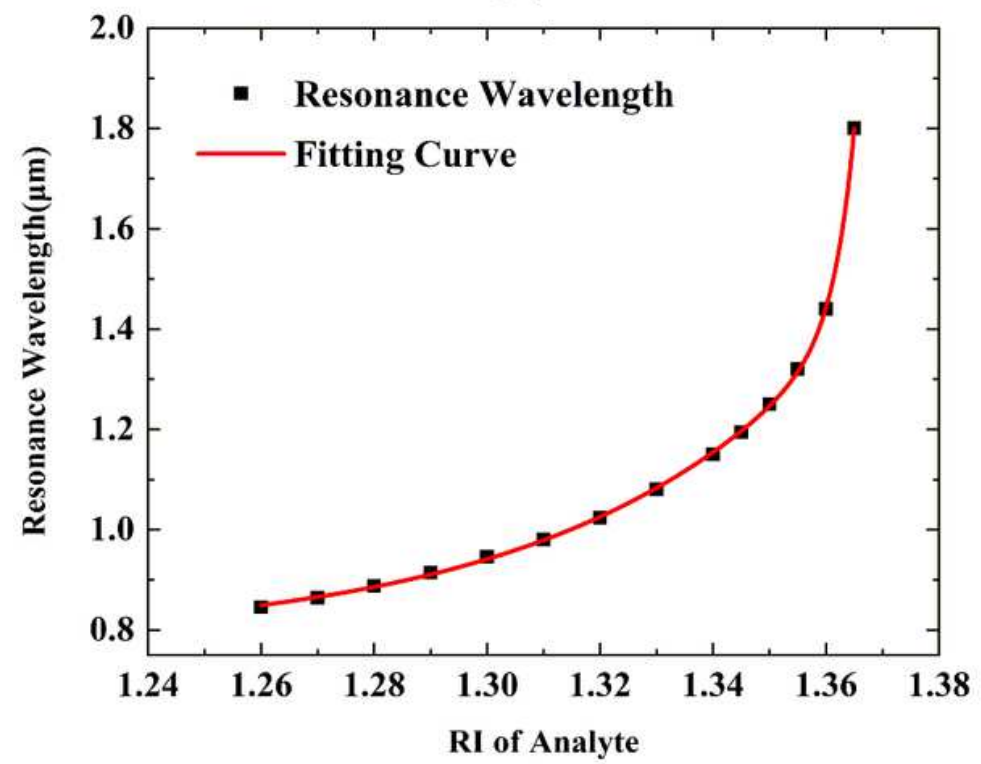

(c)

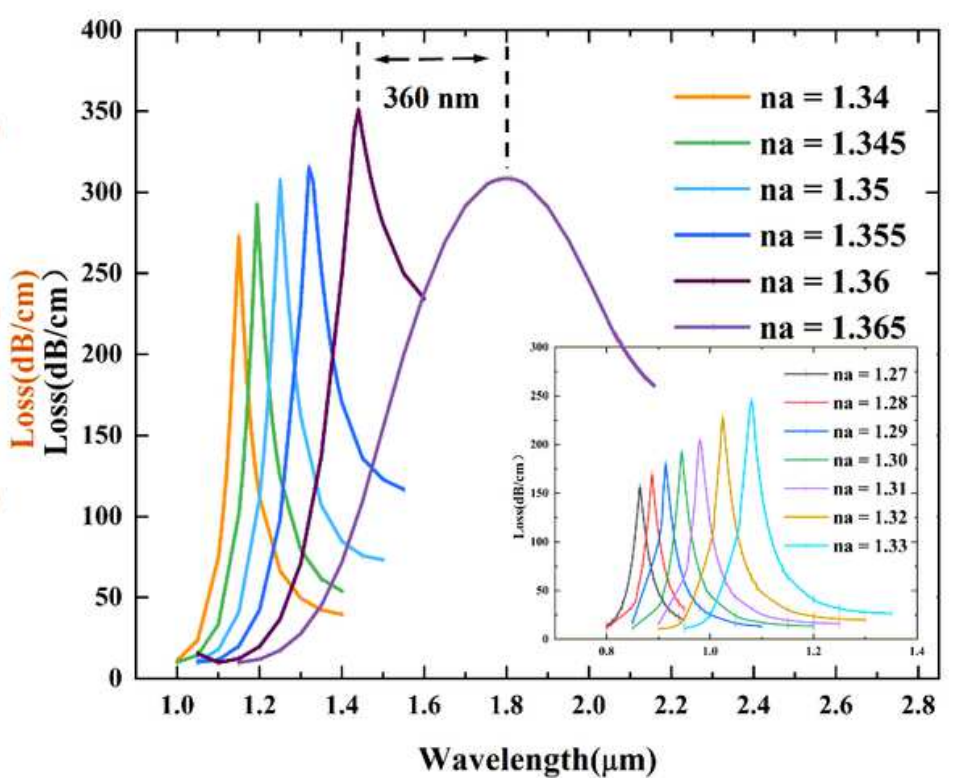

(b)

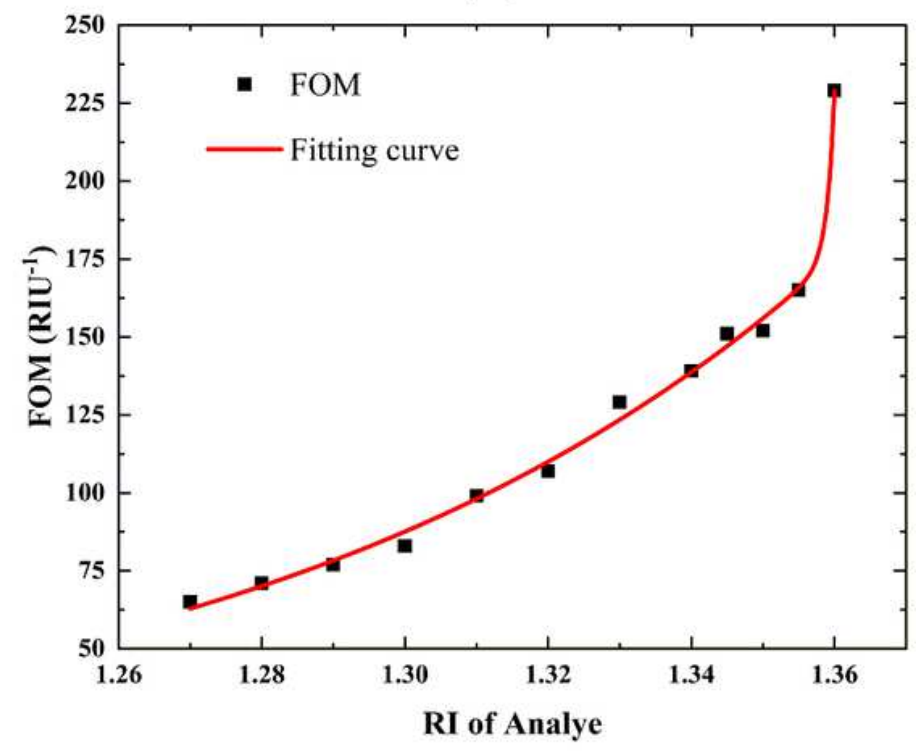

(d)

Figure 3

Dispersion relation of fundamental core mode, SPP mode, and loss spectra of na = 1.35 (a), confinement loss (b), resonance wavelength versus RI of the analyte (c) , FOM fitting curve for analyte RI variation (d). 

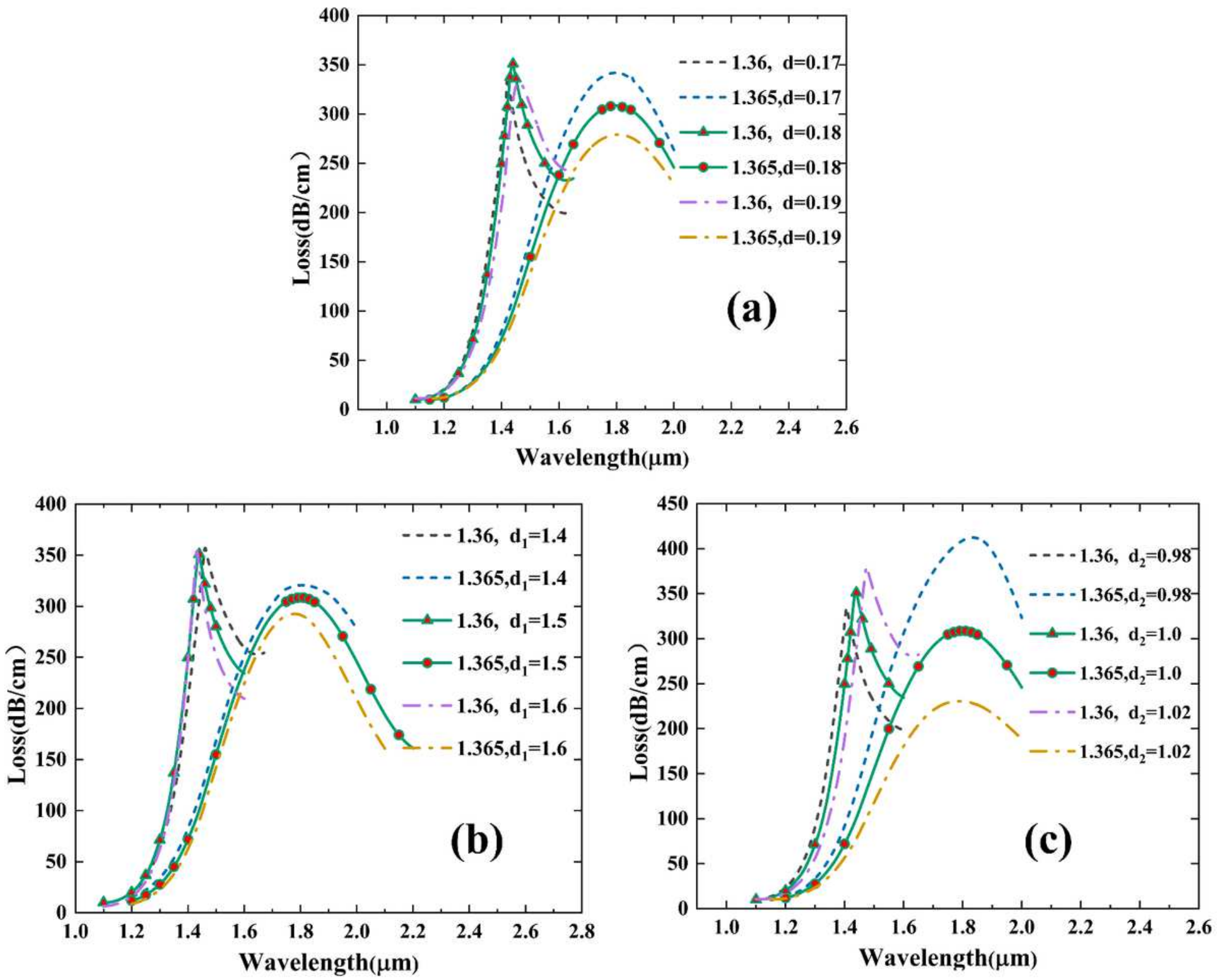

Figure 4

(a) Confinement loss spectra at different diameter of core. (b-c) Confinement loss spectra for different air hole diameter $\mathrm{d} 1, \mathrm{~d} 2$. 

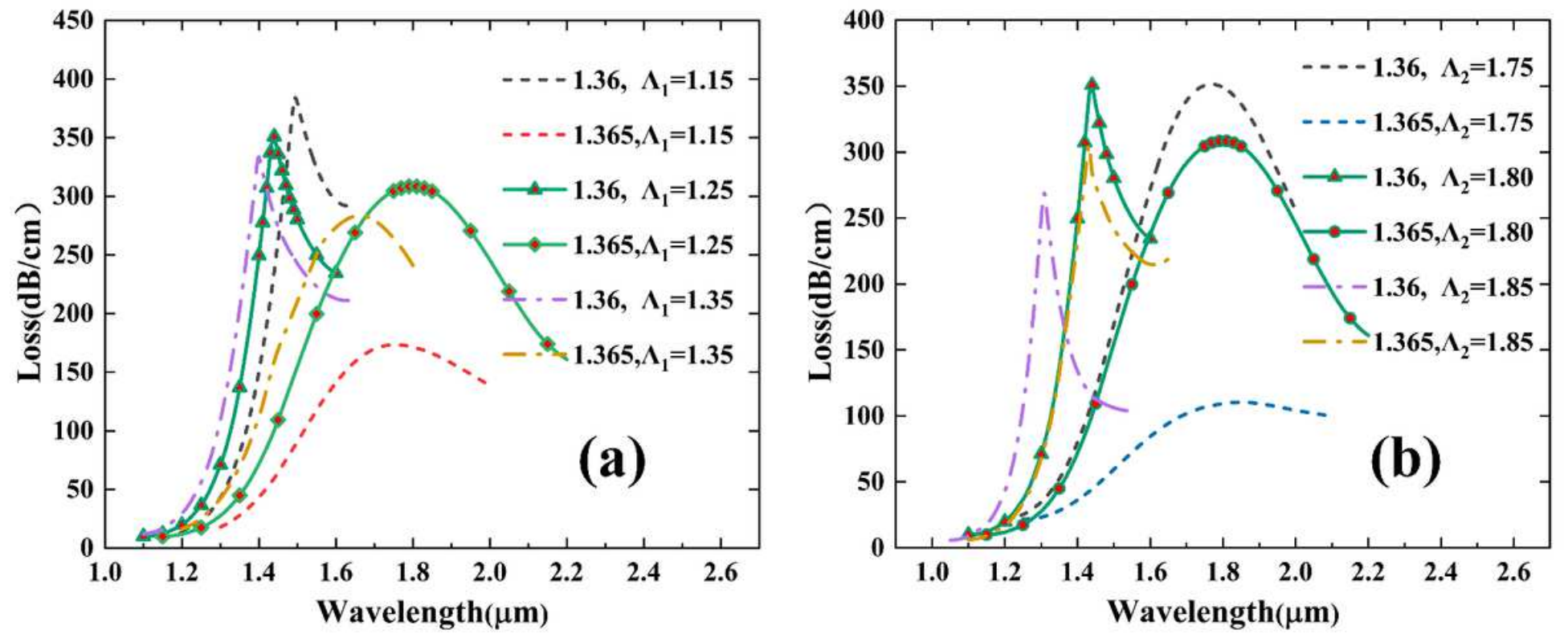

Figure 5

(a-b) Confinement loss spectra with varying pitch distance $\wedge 1, \wedge 2$. 

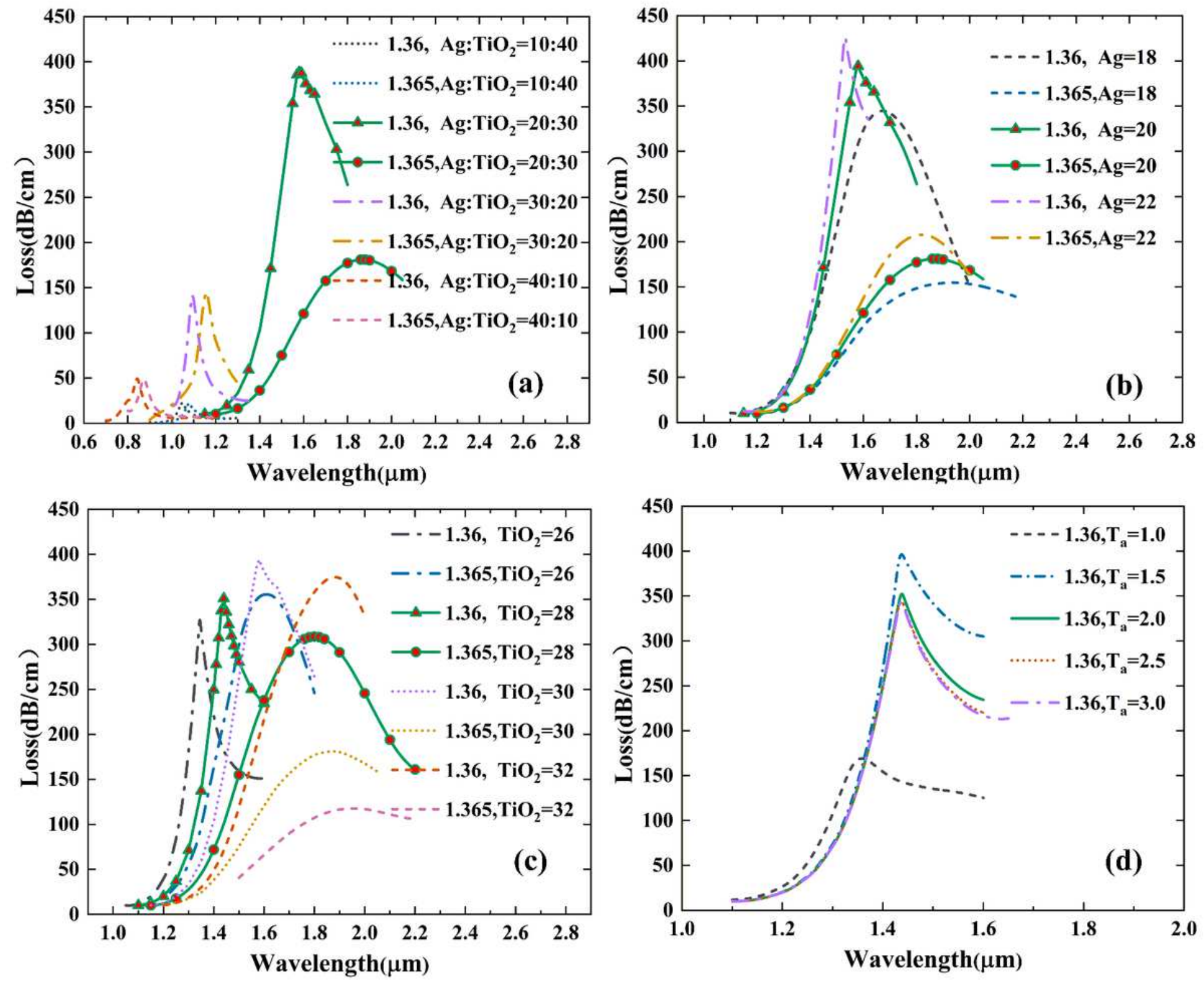

Figure 6

(a)Confinement loss spectra at different ratio of $\mathrm{Ag}$ and TiO2 film thickness. (b)Confinement loss spectra for different Ag film thickness at TiO2 film thickness $=30 \mathrm{~nm}$. (c)Confinement loss spectra for different TiO2 film thickness at Ag film thickness $=20 \mathrm{~nm}$. (d)Confinement loss spectra at different analyte channel thickness variation. 